http://dx.doi.org/10.21611/qirt.1994.048

\title{
IR detection limit of underground structure by thermal image technique
}

\author{
by OKAMOTO $Y^{\star}$,LIU C. , FAN Z." and INAGAKI T.*
}

*Ibaraki University, 4-12-1, Nakanarusawa, Hitachi, Ibaraki, Japan, 316

Abstract

A thermal image technique had been developed to detect internal flaws of industrial structural elements as a remote sensing device. This method was applied to detect the underground and obscured structural elements,like piping, vessel,concrete and ancient tomb,by solar and artificial heating. Detection limit of underground test pieces was represented by the experiment. Numerical calculation was carried out to analyses heat flow mechanism around the test piece.

Nomenclature

a; thennal diffusivity

n;normal direction

$q$;heat flux

\section{T;temperature}

$x$, horizontal coordinate

$y$,vertical coordinate

\section{Greek Symbols}

\author{
a;heat transfer coefficient \\ $\lambda$; thermal conductivity \\ $\theta$;dimensionless temperature \\ $\tau$;time
}

\section{Introduction}

An infrared radiometer was used to detect internal flaws,like crack, pinhole and inclusion of industrial structural elements, as one of remote sensing devices. A noble quantitative IR testing method,so called a thermal image detection method, was conducted to detect internal flaws of mechanical components during operation."

The method was carried out by visualizing deformation of radiation temperature distribution of the tested surface above the internal flaws by the active heat injection. ${ }^{2)}$ The induced non-uniform temperature shows the existence of the internal flaws. And two-dimensional temperature distribution was displayed on the CRT of the infrared radiometer. ${ }^{3)}$

The method had been already applied to detect the underground structural elements,like pipe,vessel,pile,concrete slab,for industrial use. A new object imaging and detection of underground structure of ancient remains, like corner stone, stone settlement ,shell mound and tomb was conducted by means of the infrared radiometer. The paper represents a preliminary model test of those remains to determine the detection limit of rectangular test plates buried in underground by artificial heat injections of the sun and combustion flame. The temperature and its distribution on the surface above the buried tests plate becomes nonuniform and discontinuous.

Such abnormal temperature distribution shows the existence of the underground object. We carried out to determine the detective dimension of the object with the depth $\mathrm{H}$ and width $\mathrm{b}$ as parameters.

Furthermore,transient temperature and heat flow mechanism were analysed by solving a transient two-dimensional heat-balance equation. Numerical calculation result was quite useful to analyses the heat transfer behavior around the underground object. Numerical data were compared with experimental results.

\section{Test apparatus and experimental method}

Several rectangular test plates consist of styrene foam, concrete, stone and gravel to simulate. the object of the ancient remains as ,already mentioned in section 1.

Figure 1 shows schematic illustration of the test piece. Three buried styrene foam plates,as denoted in A,B and C,are rectangular and buried in the soil of 10,20 and $40 \mathrm{~cm}$ in depth $\mathrm{H}$. Two concrete rectangular plates and gravel layer are also buried in the soil.A stone plate was put on the surface of the soil.

Figure 2 shows the schematic illustration of a test apparatus. The test plates of the styrene,concrete,stone and gravel are buried in the soil.Chromel-alumel thermocouple wires 
http://dx.doi.org/10.21611/qirt.1994.048

are set up on the upward and downward surfaces of the test plates to measured the temperature and are connected to a data recorder. Radiation temperature distribution of the soil surface with internal test plates is visualized from upward using the infrared radiometer by solar heating and atmospheric cooling ,as shown in the figure. To detect the deep buried test plates of over $40 \mathrm{~cm}$ in depth,corrugated cardboard papers on which the light oil was sprayed are set on the soil surface.The artificial high-flux burning test was carried out by burning the corrugated papers.After burning up,we removed the ash of the burned paper.And we started the observation by the infrared radiometer.

We measured the temperature of the buried test plates by thermocouples and temperature distribution of the soil surface using the infrared radiometer. Measuring time was about two days and sampling time of the temperature and IR image was one hour.We recorded also the solar injected heat flux and air velocity in same time. To obtain the high heat flux heating,we used fire burning .Time of the fire burning is about five minute. We recorded the temperature and IR photograph for every one minute during total measuring time of $\mathbf{3 0}$ minute.

\section{Experimental test result}

Fig.3 shows the thermograph of buried styrene plates at $10 \mathrm{~cm}$ in depth. Mountainous temperature distribution shows the existence of the buried plates in zenith.

Fig.4. shows the thermograph of buried styrene plates in the evening. We can observe the concave temperature distribution above the buried plates.

Time-dependent temperature distribution of the tested plate at $10 \mathrm{~cm}$ in depth was measured by thermocouples, as shown in Fig.5. According to time-dependent solar heat flux and atmospheric temperature $T_{a}$, the surface temperature $T_{1}$ is increasing in the morning and decreasing in the afternoon with time lag. The temperature change of the surface of the test plate in the soil $T_{2}$ and $T_{3}$ is smaller than $T_{a}$ and $T_{1}$.

Fig.6 shows the temperature difference of styrene plates $A, B, C$ by thermocouples Tc. Maximum temperature difference of the big styrene test plate $A$, as shown in Fig. 1 , is $4.5^{\circ} \mathrm{C}$ in zenith. Value of $\Delta \mathrm{Tc}$ in the night becomes minus and decreases to minus $2.5^{\circ} \mathrm{C}$ early in the morning.

Figure 7 shows time-dependent temperature difference of the mortar plate and gravel $\mathrm{D}, \mathrm{E}, \mathrm{G}, \Delta \mathrm{Tc}$ by thermocouple. The temperature rise of the gravel is largest,and value of Tcmax at $D, E, G$ becomes 4,0 and $8^{\circ} \mathrm{C}$.

Figure 8 shows time-dependent temperature difference of the stone $S$ by thermocouple $\Delta$ Tc. The temperature rise in daytime becomes $8^{\circ} \mathrm{C}$ and the temperature drop in the night becomes -1 to $4^{\circ} \mathrm{C}$ which depends on environmental condition, like the velocity, albedo ratio, heaven and air temperature.

Table 1 represents maximum positive and negative temperature difference of buried test plates $\Delta T \mathrm{cmax}$ at $10 \mathrm{~cm}$ in depth except datum of the stone settled in the surface. Values of $\Delta$ Tcmax become positive in the daytime near the zenith and negative in the night. Heat injection condition in the daytime and night is shown in the Table. The artificial high-flux burning test was carried out by burning the corrugated papers in which the light oil is contained.

Figure 9 shows thermograph of deep buried styrene plates of $40 \mathrm{~cm}$ in depth by fire burning. After burning time of 5 minute, we visualize the hot zone of the buried styrene plates on the thermograph. The initial injected heat flux is about $5 \mathrm{w} / \mathrm{cm}^{2}$.

\section{Numerical analysis}

\subsection{Heat balance equation}

Figure 10 shows the numerical calculation model of the buried test piece. A buried rectangular cavity EFGH ,thermo-physical properties of which are different from that of the surrounding space ABCD.Solar and combustion flame injects the heat flux $q$ to the surface $A B$ and the injected heat is transferred to the space by the heat conduction and the environment to the heat convection and radiation.Temperatures of the space and cavity $T_{1}(x, y, \tau)$ and $T_{2}(x, y, \tau)$ are expressed in

$$
a_{1}\left(\partial^{2} T_{1} / \partial x^{2}+\partial^{2} T_{1} / \partial y^{2}\right)=\partial T_{1} / \partial \tau
$$


http://dx.doi.org/10.21611/qirt.1994.048

$$
a_{2}\left(\partial^{2} T_{2} / \partial x^{2}+\partial^{2} T_{2} / \partial y^{2}\right)=\partial T_{2} / \partial \tau
$$

Boundary conditions are shown in

at $\mathrm{AB}$ surface; $-\lambda_{1} \partial \mathrm{T}_{1} / \partial \mathrm{x}+\left(a_{\mathrm{c}}+a_{\mathrm{r}}\right)\left(\mathrm{T}_{1}-\mathrm{Tg}\right)=\mathrm{q}(\tau)$

at BCDA surfaces; $\lambda_{1} \partial \mathrm{T}_{1} / \partial \mathrm{n}=0$

at EFGH surfaces; $\lambda_{1} \partial \mathrm{T}_{1} / \partial \mathrm{n}=\lambda_{2} \partial \mathrm{T}_{2} / \partial \mathrm{n}$

Where $\alpha$ and $\alpha$ are the convective and radiative heat transfer coefficients. Solving equations (1) and (2), we obtain the transient temperature of the space and cavity $T_{1}(x, y, \tau)$ and $\mathrm{T}_{2}(\mathrm{x}, \mathrm{y}, \tau)$.

\subsection{Calculation results}

Figure 11 shows two-dimensional temperature distribution of the space with the cavity of $10 \mathrm{~cm}$ in depth $\mathrm{H}$ by solar heating. The solar injected heat flows around the cavity. The expansion flow around the cavity causes mountainous temperature distribution at the surface,already shown in the experimental result.

Figure 12 shows the time-dependent temperature of the buried test piece at $b=40 \mathrm{~cm}$ and $\mathrm{H}=10 \mathrm{~cm}$. The temperature above the cavity Tc becomes larger than that of the surface without the internal cavity Ts in daytime and becomes smaller than that in the night.And therefore,the temperature difference $\Delta T c=T c-T s$ is shown in a one-dotted line.

Figure 13 shows the time-dependent temperature of the buried test piece at $b=40 \mathrm{~cm}$ and $\mathrm{H}=20 \mathrm{~cm}$. The temperature $\mathrm{T}_{1}, \mathrm{~T}_{2}$ and temperature difference $\Delta \mathrm{Tc}=\mathrm{T}_{1}-\mathrm{T}_{2}$ are smaller than that of $\mathrm{H}=10 \mathrm{~cm}$. The temperature difference $\Delta \mathrm{Tc}$ is decreasing with increase in the depth $\mathrm{H}$ and inverse of the width $b$.

Figure 14 represents the time-dependent temperature difference $\Delta \mathrm{Tc}$ with the depth $\mathrm{H}$ as a parameter. The time which shows the maximum temperature difference $\Delta$ Tcmax by solar heating $\tau_{\max }$ is increasing with increase in the depth $\mathrm{H}$. And $\Delta$ Tcmax of the soil is increasing with increase in the width $b$ and inverse of the depth $\mathrm{H}$. We can estimate the depth $\mathrm{H}$ and width $B$ by measuring the maximum temperature difference $\Delta$ Tcmax and the time $\tau_{\max }$.

Table 2 shows the relation between the depth $\mathrm{H}$ and maximum temperature difference $\Delta$ Tcmax with the depth $\mathrm{H}$ as a parameter. $\Delta \mathrm{Tcmax}$ of the soil is larger than that of the rock and decreasing with increase in the depth $\mathrm{H} . \Delta$ Tcmax of the rock becomes smaller than that of the soil. The numerical result represents that we can detect the deep cavity of the soil and rock up to the depth of $60 \mathrm{~cm}$. But,we were unable to detect the cavity of over $40 \mathrm{~cm}$ in the depth by the experiment.

\section{REFERENCES}

[1] OKAMOTO (Y.), INAGAKI (T.), NUMAO (T.), FUKAZAWA (N.); Remote sensing study of flaw of structural material, Proc. of SPIE Thermosense, April, (1993), Orlando, USA, p. 215.

[2] OKAMOTO (Y.), NAKAMURA (H.), INAGAKI (T.), QUOKA (N.); Visualization of intemal flaw and leak components by means of infrared radiometer, Proc. of Fall Conf. ASNT, Oct., (1993), Long Beach, USA, p. 67.

[3] OKAMOTO (Y.), KAMINAGA (F.), QUOKA (N.) TSUYUZAKI (N.); Remote sensing infrared image study of detecting extemal and intemal flaws by means of active themal incidence, NonDestructive Testing 92, Oct., (1992) San-Paolo, Brazil, p. 730. 
http://dx.doi.org/10.21611/qirt.1994.048

Fig.1 Schematic Illustration of the test plece

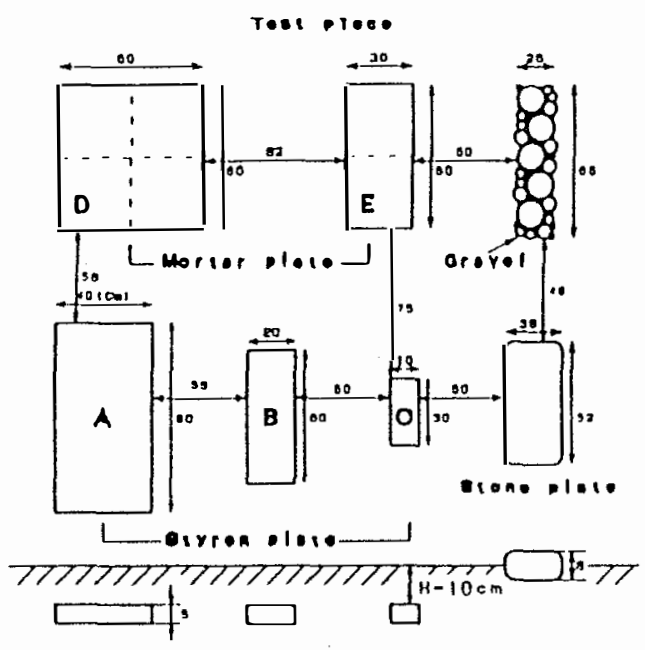

Fig.2 Schematic lliustration of test apparatus

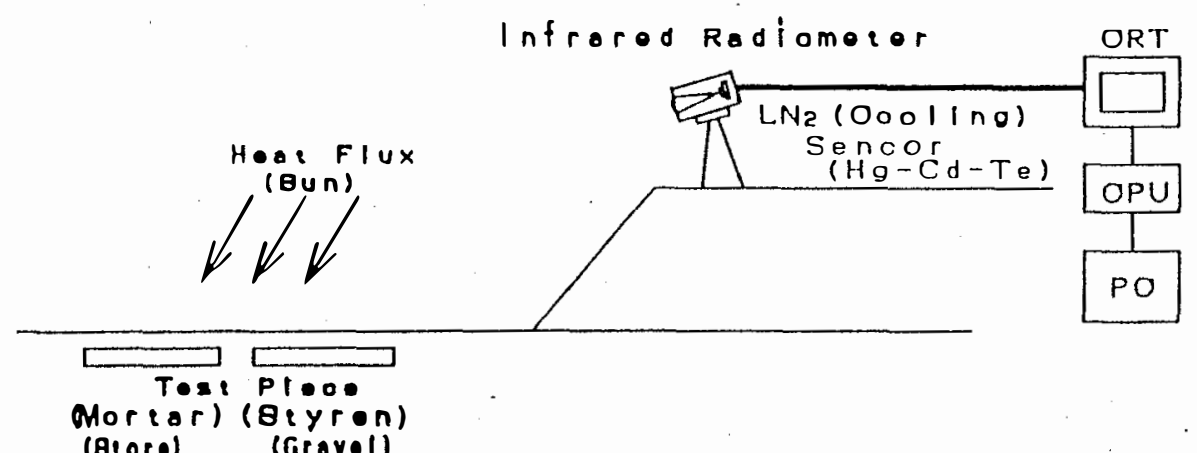

Fig.3 Thermograph of burled styrene plate

Fig.4 Thermograph of styrene plate (No A,B,C,H=10cm, 18:30,23,Nov, 1993) (No A,B,C,H=10cm,11:30,23,Nov.1993)
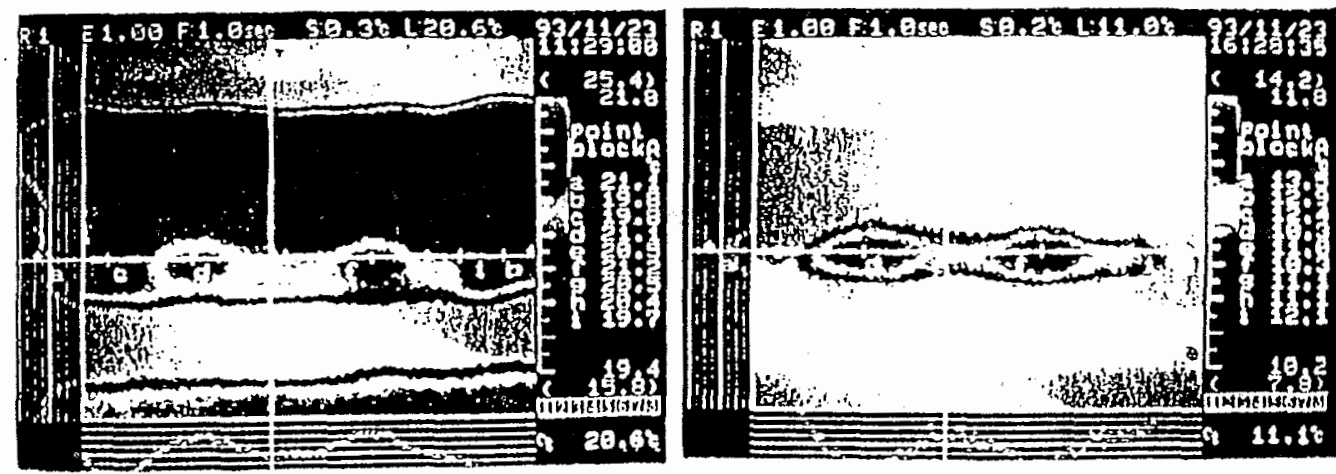
http://dx.doi.org/10.21611/qirt.1994.048

Fig.5 Time-dependent temperature of of styrene plates $\mathbf{A}, \mathbf{B}, \mathbf{C}$ by thermocouples (17:30,7,Feb,--22:00,8,Feb,1994)

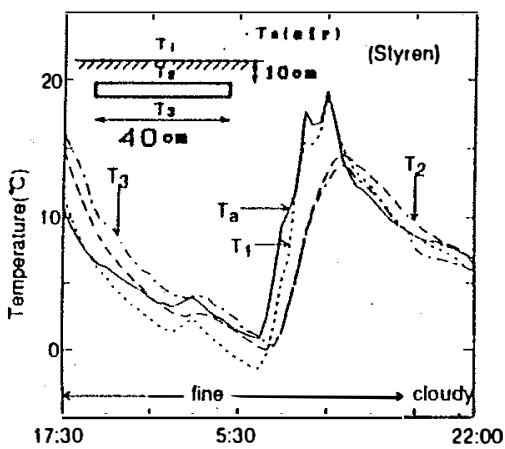

FIg.7 Time-dependent temperature difference of mortar plate D,E,G by thermocouples (6:00,--22:00,15,Feb, 1994)

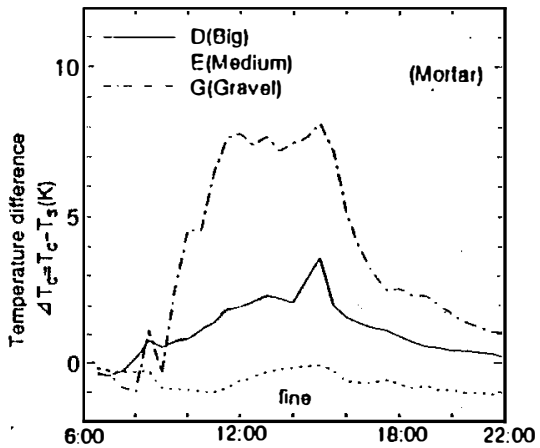

Flg.9 Thermograph of burled styrene temperature difference of burled plates (17:30,--22:00,7,Feb,1994)

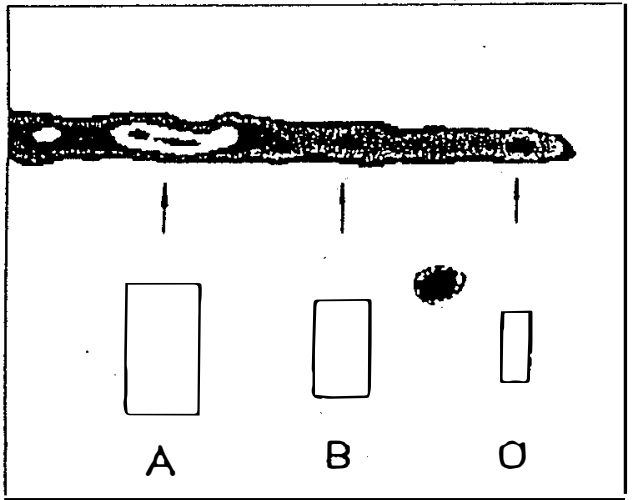

Fig.6 Time-dependent temperature difference styrene plate $A$ by thermocouples

(17:30,7,Feb,--22:00,8,Feb,1994)

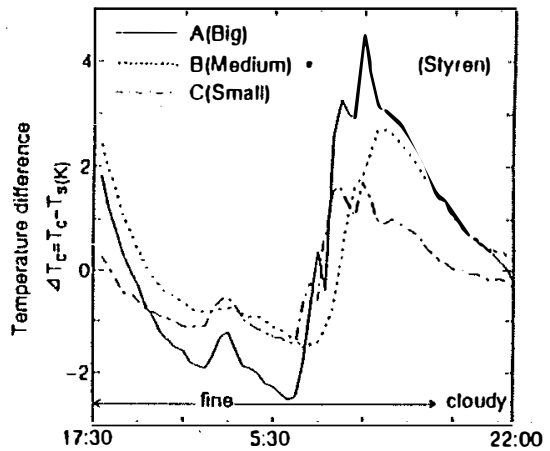

FIg.8 Time-dependent temperature difference of stone $\mathbf{S}$ by thermocouples

(6:00,--22:00,15,Feb,1994)

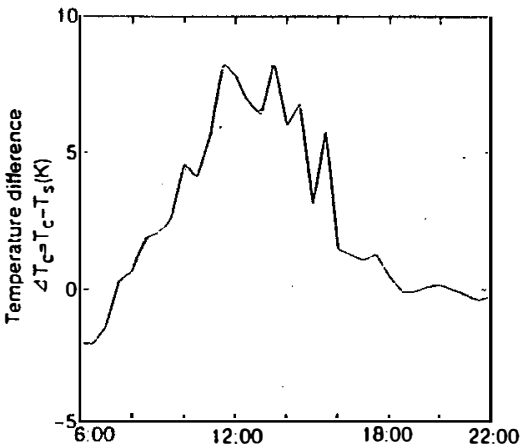

Table.1 Maximum positlve and negatlve plates by fire burning plates $\Delta$ Tcmax (12:00,29,July,1994)

\begin{tabular}{|c|c|c|}
\hline $\begin{array}{l}\text { Type } \\
\text { unite }\end{array}$ & $\begin{array}{l}\text { daytime } \\
\left.+\Delta T^{\circ}{ }^{\circ} \mathrm{C}\right)^{\circ \cdot}\end{array}$ & $\begin{array}{l}\text { night } \\
- \text { oT. max } \\
\left.\text { ( }{ }^{\circ} \mathrm{C}\right)^{m=}\end{array}$ \\
\hline siylene & 6 & -2 \\
\hline concrete & 2.5 & -0.5 \\
\hline stone & 8 & -1 \\
\hline gravel & 8 & -1 \\
\hline
\end{tabular}

$q_{. .0}=5.67 \times 10^{-8}\left(T^{4}-283^{4}\right)\left(\mathrm{w} / \mathrm{m}^{2} \mathrm{k}\right)$

$q_{c o n v}=10(T-293-5 \sin x((r-6) / 12)$

$q_{\text {. } u n}=500 \sin (s / 12)$, $T(0)=288 \mathrm{~K}$

6-18 o clock; $q=q_{\text {. un }}-q_{\text {conv }}-q_{\text {.. o }}$

18-6 o clock; $q=-q_{\text {oonv }}-q_{\text {r.d }}$ 